\title{
Use of Online Self-Management Diaries in Asthma and COPD: A Qualitative Study of Subjects' and Professionals' Perceptions and Behaviors
}

\author{
Valerie van Kruijssen MSc, AnneLoes van Staa RN MD MA PhD, Jolanda Dwarswaard PhD, \\ Johannes CCM in 't Veen MD PhD, Bianka Mennema MD, and Samantha A Adams PhD
}

\begin{abstract}
BACKGROUND: Online self-management diaries are used to support patients' self-management skills and facilitate associated behavioral changes. Although web-based diaries are well-known as a potential self-management tool, reasons that patients use (or do not use) self-management diaries, as well as perceptions and behaviors related to diary use, remain largely unknown. METHODS: Semistructured interviews $(n=30)$ were conducted with health-care professionals and subjects to understand perceptions and behaviors related to self-management diary use for asthma and COPD in 2 hospitals in Rotterdam, The Netherlands. RESULTS: Subjects in this study used self-management diaries to improve their knowledge of the disease, cope more consciously with their disease, feel in control, and discuss outcomes from the self-management diaries with their health-care professionals. Two subjects reported that they used the self-management diary to cope more effectively with their disease and recognized an exacerbation and acted by adjusting their medications. Both health-care professionals and subjects experienced practical barriers in integrating self-management diaries into their regular practices. Subjects' reasons for nonuse were related to the intervention, the disease, and subject-provider contact. CONCLUSIONS: Health-care professionals should help patients use self-management diaries by collaboratively developing an individual treatment plan and by showing patients how to use the diaries to recognize and act on an exacerbation. Together with the suggestions made for improving the self-management diaries, this will aid in the integration of self-management diaries into regular health-care practice and enhance patients' self-management of their disease. Key words: chronic disease; self-management; patient education; health-care technology; online self-management diaries; asthma; COPD. [Respir Care 2015;60(8):1146-1156. (C) 2015 Daedalus Enterprises]
\end{abstract}

\section{Introduction}

Asthma and COPD are common chronic obstructive airway diseases. Asthma is an inflammatory (often allergic) airway disease that develops typically in childhood, is char-

\footnotetext{
Ms van Kruijssen and Dr van Staa are affiliated with the Institute of Health Policy \& Management, Erasmus University Rotterdam, Rotterdam, The Netherlands. Drs van Staa and Dwarswaard are affiliated with the Centre of Expertise Innovations in Care, Rotterdam University of Applied Sciences, Rotterdam, The Netherlands. Dr in 't Veen is affiliated with the Department of Pulmonology, Sint Franciscus Gasthuis, Rotterdam, The Netherlands. Dr Mennema is affiliated with Harbor Hospital, Rotterdam, The Netherlands. Dr Adams is affiliated with the Tilburg Institute for Law, Technology, and Society, Tilburg University, Tilburg, The Netherlands.
}

acterized by episodes of reversible air-flow obstruction, and generally responds well to anti-inflammatory treatment. In contrast, COPD is typically caused by tobacco smoking, develops in mid to later life, and is characterized

\footnotetext{
Dr in 't Veen presented a version of this paper at the European Respiratory Society International Congress, held September 6-10, 2014, in Munich, Germany. Ms van Kruijssen presented a version of this paper as part of her master's thesis defense.
}

The authors have disclosed no conflicts of interests.

Correspondence: AnneLoes van Staa RN MD MA PhD, Institute of Health Policy \& Management, Erasmus University Rotterdam, PO Box 1738, 3000 DR Rotterdam, The Netherlands. E-mail: vanstaa@bmg.eur.nl.

DOI: $10.4187 /$ respcare.03795 
by irreversible air-flow limitation that results in a progressive decline in lung function, loss of quality of life, and potential premature death. ${ }^{1}$

For chronic diseases such as asthma and COPD, patients are encouraged to actively participate in their care and treatment and to self-manage their health and illness. ${ }^{2}$ In this study, self-management is defined as:

\begin{abstract}
The individual ability to manage the symptoms, treatment, physical and psychosocial consequences and lifestyle changes inherent in living with a chronic condition. Efficacious self-management encompasses ability to monitor one's condition and to effect the cognitive, behavioral and emotional responses necessary to maintain a satisfactory quality of life. Thus, a dynamic and continuous process of self-regulation is established. ${ }^{3}$
\end{abstract}

Goals of self-management in chronic diseases include minimizing symptoms and optimizing treatment, as well as managing the physical and psychosocial consequences and lifestyle changes inherent in living with a chronic disease. ${ }^{4}$ Approaches to accomplishing this may address the ability to recognize and to respond to symptoms with optimization of medication use and management of behavioral issues such as the promotion of physical activity, smoking cessation, and social interactions. ${ }^{2}$ Literature has shown that self-management approaches can improve patients' knowledge of their disease and treatment and increase their motivation and confidence that the disease can be controlled, thereby improving treatment adherence and symptom management and control.5,6

Online self-management diaries are tools that are used to support the development of patients' self-management skills and facilitate associated behavioral changes. Such diaries are web-based (personalized) diaries that provide patients a space to produce personal health information and share similar attributes with self-management action plans (for example, helping patients develop goal setting with an individual treatment plan), but may also offer other functions (such as an e-consult). ${ }^{7}$ Although webbased diaries have existed a long time, developments in web technologies (primarily the development of blogging platforms ${ }^{8}$ ) have made them easier to use, broadening the scope of the target group for whom they may be beneficial.

Previous research on self-management strategy use has generally focused on other tools (eg, self-management education) and often used medical outcome measures (eg, lung function) or health-care consumption (eg, hospital admission) to evaluate their success. ${ }^{2,5,6,9,10}$ The few studies that did examine subjects' reasons for using self-management strategies reported explanations such as having a fixed daily routine and following the advice given by their

\section{QUICK LOOK}

\section{Current knowledge}

Asthma and COPD are common, chronic, worldwide respiratory diseases. Self-management is an important component of a patient's care plan. Online self-management diaries can be used to support patients' selfmanagement skills and facilitate behavioral changes. Patients' and caregivers' perceptions and use of online tools are not well known.

\section{What this paper contributes to our knowledge}

Health-care professionals and subjects reported positive attributes of online self-management diaries. However, both reported practical barriers to use of the selfmanagement diaries in daily life. Recommendations to enhance the use of these tools include a web-based consult system, development of handheld applications, and improved user-friendliness.

doctor. ${ }^{11}$ Reasons for not using self-management strategies included forgetfulness, belief that the medication was ineffective, not feeling any benefit, lack of perceived symptoms, denial that they have asthma, difficulty in using inhalers, inconvenience, fear of adverse effects, embarrassment, and laziness. ${ }^{11-14}$ However, patients' reasons, perceptions, and behaviors in relation to using (or not using) self-management diaries remain largely unknown. Because existing studies $2,5,6,9-14$ are limited in scope and setting and focus merely on the subject, thus neglecting the role of the caregiver, the findings of these studies may not be transferable between patient types and settings. The aim of this qualitative study was to understand health-care professionals' and subjects' perceptions and behaviors related to selfmanagement diary use.

\section{Methods}

\section{Study Design}

Given the explorative nature of this study, a qualitative approach was used. Qualitative studies aim to provide an understanding of complex issues relating to human behavior. ${ }^{15}$ Semistructured interviews were used to study the use and nonuse of self-management diaries for asthma and COPD (Curavista Health 3.0, Geertruidenberg, The Netherlands) in 2 teaching hospitals in Rotterdam, The Netherlands. All interviews were digitally recorded and transcribed verbatim. Data were analyzed by checking or comparing each item with the rest of the data to establish analytical categories, also known as constant comparison. ${ }^{16}$ 
Table 1. Elements of Asthma and COPD Self-Management Diary

\begin{tabular}{|c|c|}
\hline Elements & Descriptions \\
\hline \multicolumn{2}{|l|}{ General } \\
\hline Symptoms and actions & $\begin{array}{l}\text { Subjects are able to define } 3 \text { different health states (green, orange, red) with corresponding } \\
\text { symptoms and actions. Furthermore, they are able to keep track of when they are experiencing } \\
\text { these different health states and receive reminders for previously defined actions to manage } \\
\text { their health status. This urges subjects to judge their own health and supports them in } \\
\text { recognizing symptoms. }\end{array}$ \\
\hline Personalized goal & $\begin{array}{l}\text { Subjects are able to define what they would like to accomplish with the treatment and are able } \\
\text { to indicate to what extent they have accomplished this goal. A comparison between the } \\
\text { personalized goal and the actual accomplishment is then produced. Again, subjects are urged } \\
\text { to judge their own health. }\end{array}$ \\
\hline Medication use & $\begin{array}{l}\text { Subjects are able to write down which medications and what dosage they (normally) use, which } \\
\text { increases insight into their medication use. }\end{array}$ \\
\hline E-consult & $\begin{array}{l}\text { Subjects may request advice or information from health-care professionals in an easy manner and } \\
\text { at convenient times. }\end{array}$ \\
\hline \multicolumn{2}{|l|}{ Specific } \\
\hline Validated questionnaires & $\begin{array}{l}\text { Subjects are asked to recall how their disease has been during the week. To fill in these } \\
\text { questionnaires, subjects again must judge their own health status, which supports them in } \\
\text { recognizing symptoms. }\end{array}$ \\
\hline $\begin{array}{l}\text { Exacerbations (deterioration of lung } \\
\text { complaints that requires } \\
\text { modification of medication use) }\end{array}$ & $\begin{array}{l}\text { Subjects are taught to recognize and handle an exacerbation by composing a personal definition } \\
\text { of an exacerbation and by keeping track of the number of exacerbations they have } \\
\text { experienced, impact on their health status, and actions taken to counteract these exacerbations. }\end{array}$ \\
\hline Self-tests & $\begin{array}{l}\text { Subjects are asked questions about their smoking, exercise, and weight. These self-tests increase } \\
\text { subjects' awareness of smoking, exercise, and weight and provide treatment options to manage } \\
\text { these health behaviors. }\end{array}$ \\
\hline
\end{tabular}

Quotations that were used in this paper were translated from Dutch to English by the first author (a native Dutch speaker) and verified by the last author (a native English speaker with a certification of Dutch as a second language).

\section{Study Population}

Participants in this study were pulmonologists, pulmonary nurse practitioners, and subjects recruited from 2 teaching hospitals. Because multiple factors can contribute to various forms of nonuse ${ }^{17}$ and to shaping technologies in practice, we found it important to equally consider both use and nonuse of self-management diaries. Therefore, both subjects who indicated they used the self-management diaries and those who indicated that they did not were interviewed.

\section{Subject Selection}

Subject selection was performed by pulmonary nurse practitioners and was based on purposive sampling. In purposive sampling, important variables are already identified, and it is often known where respondents who meet the criteria can be found. ${ }^{18}$ To examine subject experiences with use and nonuse of self-management diaries, subjects needed to meet the following criteria: (1) diagnosed with asthma or COPD and (2) using or not using self-management diaries. Subjects who were not using selfmanagement diaries had been given access to a diary (their health-care provider created an account for them) but had either never started using the diary or had used it for a certain period of time and subsequently stopped. At the time this study was conducted, $\sim 160$ subjects owned a self-management diary in the 2 hospitals, which was $5 \%$ of the total number of subjects treated for asthma or COPD. Maximum variation was pursued by considering age, sex, condition, and use/nonuse. Age and sex were considered because research has shown that female subjects have higher self-management abilities ${ }^{19}$ and that self-management abilities decline as the subject ages. ${ }^{20}$ Using the aforementioned criteria, 32 of the 160 subjects owning a self-management diary were selected to participate in the study. Subjects were contacted by e-mail and telephone. In addition, health-care professionals $(n=4)$ were contacted by e-mail, and interviews were conducted face-to-face.

\section{Intervention: Online Self-Management Diary}

The self-management diary that was offered to subjects consisted of both general elements and elements specific to the individual subject's disease and treatment (Table 1). The elements of the self-management diary enabled interaction between the subject and the self-management diary. Interaction between the subject and self-management diary occurred, for example, when a subject kept track of 


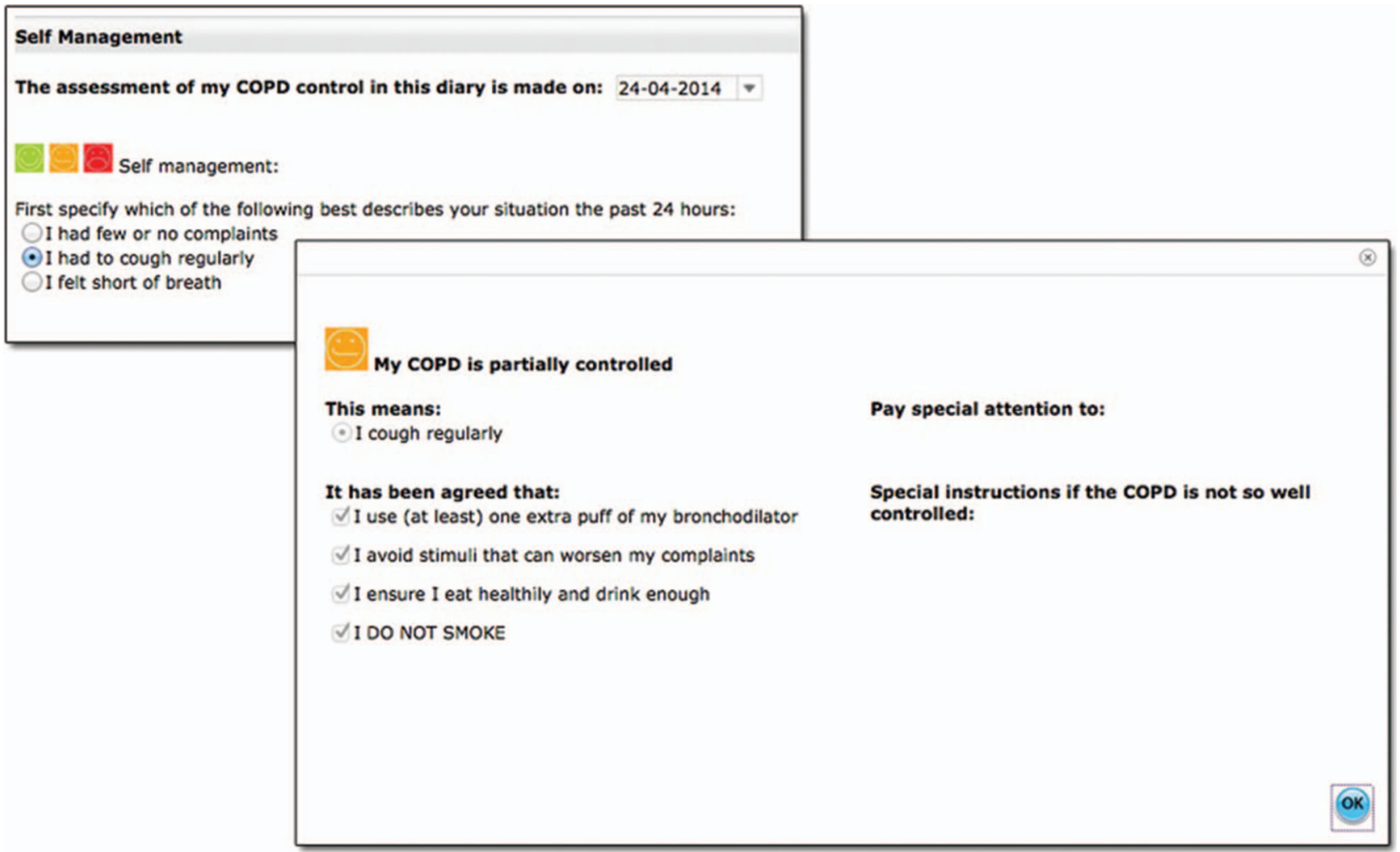

Fig. 1. Screenshot of an English version of the self-management diary, which is different from the Dutch version used in this study. The English version is shown here to provide non-Dutch-speaking readers an impression of the self-management diary.

his/her progress and immediately received feedback (eg, in the form of a question or advice that popped up within the application) (Fig. 1). In addition, more subject-tailored interaction with health-care professionals was possible using the e-consult. A subject could ask for information or advice from a health-care professional by using the e-consult within the secure environment of the program.

Health-care professionals introduced subjects to selfmanagement diaries if they thought it would be useful for their treatment and if they thought the subjects would be able to cope with the program. If applicable, the pulmonary nurse practitioner created an account for the subject, explained how to access the self-management diary and provided an information folder. Pulmonary nurse practitioners first helped subjects start the self-management diaries at the hospital. Due to time constraint, this was later changed to subjects starting the self-management diaries by themselves at home.

\section{Ethics}

The study was approved by the research ethics committees of both hospitals. Written informed consent was obtained from all subjects.

\section{Results}

\section{Sample Population}

In total, 26 subjects participated in this study: 12 (46\%) used self-management diaries, and 14 (54\%) did not. The response to the study was $81 \%$. Six subjects did not want to participate in the study (non-response rate of 19\%). Reasons for not participating in the study included not feeling like it $(n=2)$, private circumstances $(n=2)$, being abroad $(n=1)$, or not being a patient at the hospital anymore $(n=1)$. Eighteen interviews were conducted face-to-face, and 8 were conducted by telephone. Table 2 shows an overview of the distribution of age, sex, condition, and use/nonuse. Individual subject characteristics are shown in Table 3. In addition, 2 pulmonologists and 2 pulmonary nurse practitioners (one from each hospital) were interviewed.

\section{Professionals' Reasons for Introducing Self-Management Diaries}

Health-care professionals have several reasons for introducing self-management diaries to patients. The healthcare professionals in this study, who will be referred to as 
Table 2. Subject Demographic Data

\begin{tabular}{lc}
\hline \hline \multicolumn{1}{c}{ Respondents $(N=26)$} & Values \\
\hline Asthma subjects, $n$ & \\
$\quad$ Users & 6 \\
$\quad$ Nonusers & 7 \\
COPD subjects, $n$ & \\
$\quad$ Users & 6 \\
$\quad$ Nonusers & 7 \\
Sex, $n(\%)$ & \\
$\quad$ Males & $10(39)$ \\
Females & $16(61)$ \\
Age, y & $23-81$ \\
Subject use and nonuse, $n(\%)$ & \\
$\quad$ Users & $12(46)$ \\
Nonusers & $14(54)$ \\
\hline
\end{tabular}

Table 3. Subject Characteristics

\begin{tabular}{|c|c|c|c|c|}
\hline $\begin{array}{c}\text { Subject } \\
\text { Designation }\end{array}$ & Sex & Age (y) & Diagnosis & User/Nonuser \\
\hline A & Male & 64 & Asthma & User \\
\hline B & Female & 26 & Asthma & User \\
\hline $\mathrm{C}$ & Female & 54 & Asthma & User \\
\hline D & Female & 31 & Asthma & User \\
\hline E & Female & 29 & Asthma & User \\
\hline $\mathrm{F}$ & Male & 51 & Asthma & User \\
\hline G & Female & 55 & Asthma & Nonuser \\
\hline $\mathrm{H}$ & Female & 38 & Asthma & Nonuser \\
\hline I & Male & 42 & Asthma & Nonuser \\
\hline $\mathrm{J}$ & Male & 64 & Asthma & Nonuser \\
\hline $\mathrm{K}$ & Female & 56 & Asthma & Nonuser \\
\hline $\mathrm{L}$ & Female & 23 & Asthma & Nonuser \\
\hline M & Female & 57 & Asthma & Nonuser \\
\hline $\mathrm{N}$ & Female & 81 & COPD & User \\
\hline $\mathrm{O}$ & Male & 72 & COPD & User \\
\hline $\mathrm{P}$ & Female & 61 & COPD & User \\
\hline Q & Female & 56 & COPD & User \\
\hline $\mathrm{R}$ & Female & 67 & COPD & User \\
\hline $\mathrm{S}$ & Female & NA & COPD & User \\
\hline $\mathrm{T}$ & Male & 72 & COPD & Nonuser \\
\hline $\mathrm{U}$ & Male & 63 & COPD & Nonuser \\
\hline $\mathrm{V}$ & Female & 57 & COPD & Nonuser \\
\hline W & Male & 68 & COPD & Nonuser \\
\hline$X$ & Male & 59 & COPD & Nonuser \\
\hline Y & Male & 70 & COPD & Nonuser \\
\hline Z & Female & 71 & COPD & Nonuser \\
\hline
\end{tabular}

pulmonologist or pulmonary nurse practitioner 1 or 2 , provided the reasons indicated in Table 4.

Table 4 shows that health-care professionals expected the use of self-management diaries to be beneficial for subjects' treatment in multiple ways. One pulmonary nurse practitioner doubted, however, whether subjects were willing to or capable of using self-management diaries.

$$
\begin{aligned}
& \text { My first thought was that, in our patient population, } \\
& \text { it was never going to work. A bit negative of course, } \\
& \text { but we didn't work like that at all. You get patients } \\
& \text { at the out-patient department that you want to tell } \\
& \text { all kinds of things, but you don't have the idea that } \\
& \text { they're into that. Many patients have a computer, } \\
& \text { but I didn't think that they could do it. Let me just } \\
& \text { say it in that way. Whether they would under- } \\
& \text { stand ... (pulmonary nurse practitioner 2) }
\end{aligned}
$$

As subjects' self-management abilities arguably varied, health-care professionals recognized that they may not be equally able to use self-management diaries.

\section{Subjects' Reasons for Using Self-Management Diaries}

Subjects also had specific personal reasons for using self-management diaries. In this study, subjects generally mentioned 5 reasons as outlined in Tables 5 and 6 . Subjects are denoted with the assigned randomization letters, as listed in Table 3.

A common motive for using self-management diaries was gaining insight into (the progress of) one's disease. This was mentioned by both asthma and COPD subjects irrespective of other factors such as age and sex. In addition, there were differences in the reasons for use between subjects with asthma and COPD. Whereas only subjects with asthma expressed wanting to be actively involved in their own treatment and wanting to use the diaries to achieve efficiency in exchanging information or as a means to decrease health-care consumption, one subject with COPD indicated the importance of using self-management diaries in the interest of others, reflecting an understanding that this could be used for research and improving treatment.

\section{Subjects' Reasons for Not Using Self-Management Diaries}

Although some subjects gave specific reasons for using self-management diaries, others had reasons for not using self-management diaries. Subjects in this study indicated that, although they no longer currently (or never) used the self-management diaries available to them, they had reacted enthusiastically when they first heard about them. This suggests that other factors outweighed their first positive reaction. Subjects in this study generally gave one of the reasons for nonuse displayed in Tables 7 and 8 .

A common motive for not using self-management diaries was related to the intervention. Subjects with asthma 
Table 4. Professionals' Reasons for Use

\begin{tabular}{|c|c|}
\hline Reasons for Use & Health-Care Professionals' Comments \\
\hline $\begin{array}{l}\text { Improving subject information and education } \\
\text { strategies }\end{array}$ & $\begin{array}{l}\text { ". . . and of course, I also hoped that it leads to people being less dependent on us, so that we, } \\
\text { in fact, have a better-prepared consultation. Then you can go a layer deeper, instead of }\end{array}$ \\
\hline Improving effectiveness of consultations & having to repeat the basic things. So it's a piece of information and a piece of patient \\
\hline Decreasing health-care consumption & $\begin{array}{l}\text { learning, which lead to subjects knowing better what their disease is. During a } \\
\text { consultation ... patients can ask different types of questions; they know more, so you can } \\
\text { more or less skip the basic questions and move on." (pulmonologist 1) }\end{array}$ \\
\hline $\begin{array}{l}\text { Gaining more insight into subjects' progress } \\
\text { Improving subject follow-up through } \\
\text { e-consultation }\end{array}$ & $\begin{array}{l}\text { ".. I thought it was important to be able to see in a diary how the patient is doing and to be } \\
\text { able to agree upon an individual treatment plan. I also thought the e-consult was valuable." } \\
\text { (pulmonologist 2) }\end{array}$ \\
\hline
\end{tabular}

Table 5. Asthma Subjects' Reasons for Use

\begin{tabular}{|c|c|}
\hline Reasons for Use & Subjects' Comments \\
\hline More insight into disease progress & $\begin{array}{l}\text { "Then I get an impression of when there are peaks, when it goes well, how much medication } \\
\text { I need. and whether or not I can reduce my medications." (asthma subject B) }\end{array}$ \\
\hline $\begin{array}{l}\text { Active involvement in treatment and greater } \\
\text { control over the disease }\end{array}$ & $\begin{array}{l}\text { "I liked it... It gives you the idea that you're actively involved, not that I think that's very } \\
\text { nice, but that you have the idea of some kind of adherence or control and also gain more } \\
\text { insight." (asthma subject D) }\end{array}$ \\
\hline Efficiency in exchanging information & $\begin{array}{l}\text { "It seemed to me to be a quick way to communicate... that you're able to ask questions } \\
\text { through e-mail: I think } 1 \text { or } 2 \text { days before you receive a response, sometimes immediately, } \\
\text { and sometimes a day. But that's fine. If it's acute, you call, but it [the e-consult] saves me } \\
\text { a telephone call." (asthma subject E) }\end{array}$ \\
\hline Decreasing health-care consumption & $\begin{array}{l}\text { ".. [the nurse practitioner] told me about the diaries... and that I maybe would have to } \\
\text { come to the hospital less. Yes, I thought it was fine, the fewer hospital visits the better of } \\
\text { course." (asthma subject E) }\end{array}$ \\
\hline
\end{tabular}

mentioned not perceiving an added value, the format being too rigid, or forgetfulness as reasons for not using selfmanagement diaries, whereas one subject with COPD indicated difficulty in using the diaries. Other reasons expressed by subjects with COPD included no acknowledgment of the disease, not experiencing a disease burden (and therefore forgetting about the diaries), and having a preference for face-to-face contact.

\section{Self-Management}

Through the introduction of diaries, self-management became defined in practice not only as a way to gain more knowledge and insight into one's disease but also as a means to use this insight to cope more effectively with the disease by recognizing an exacerbation and acting on it. The positive experiences of both health-care professionals and subjects with the self-management diaries are listed in Table 9.

Both asthma and COPD subjects indicated having improved insight into the course of the disease through the use of diaries. The experiences with the self-management diaries also reflected differences between asthma and COPD subjects. Only subjects with asthma expressed coping more consciously with their disease and using the self- management diaries to adjust their medications, whereas there were no experiences expressed solely by subjects with COPD.

Even though Table 9 shows only positive experiences with the self-management diaries, only subjects with asthma indicated using the insight gained to independently recognize an exacerbation. Furthermore, only 2 subjects (both young and female) used the self-management diary to adjust their medications when having an exacerbation. This shows that, although the elements of exacerbations and medication use are present in the self-management diary, subjects did not use them as expected. Some subjects failed to change how they coped with their disease, even though they had the knowledge and tools to do this: they knew what to do, but did not act accordingly. One pulmonary nurse practitioner explained that patients-before using the self-management diaries_-must be motivated to do something themselves in order for them to adjust the way they cope with their disease.

\section{Suggestions to Improve the Self-Management Diaries}

Both health-care professionals and subjects interviewed in this study made suggestions for improving the selfmanagement diaries. These suggestions referred to issues 
Table 6. COPD Subjects' Reasons for Use

\begin{tabular}{ll}
\hline \hline Reasons for Use & Subjects' Comments \\
\hline More insight into disease progress & $\begin{array}{l}\text { "I use the diary particularly for monitoring whether the disease is still the same or I should start doing } \\
\text { something." (COPD subject O) } \\
\text { Participation in the interest of others }\end{array} \begin{array}{l}\text { ". . if it's in the context of research and better treatments and for other people as well, then you } \\
\text { should just do it, I think." (COPD subject O) }\end{array}$ \\
\hline
\end{tabular}

Table 7. Asthma Subjects' Reasons for Nonuse

\begin{tabular}{|c|c|}
\hline Reasons for Nonuse & Subjects' Comments \\
\hline No perceived added value & $\begin{array}{l}\text { ". . if all goes well, I feel that, and if it doesn't go well, I can feel that, too. Such an asthma diary will not } \\
\text { change that; it doesn't give me the feeling that I will gain more control by writing down that it doesn't } \\
\text { go well or that it does." (asthma subject L) }\end{array}$ \\
\hline Format is too rigid & $\begin{array}{l}\text { "... the gradations don't fit because, for example, you can indicate if you have normal asthma or severe, } \\
\text { but not mild or something ... mild symptoms that are always present, you're not able to put this into the } \\
\text { diary. This is not useful to me." (asthma subject M) }\end{array}$ \\
\hline Forgot to use & $\begin{array}{l}\text { "Well, I think I've done it a few times and then that's diluted because I forget. Earlier, I was much more } \\
\text { involved in the internet, creating vacation blogs or whatever; now, I'm busy with myself, as well. They } \\
\text { should make an app." (asthma subject I) }\end{array}$ \\
\hline
\end{tabular}

related to content as well as use. Health-care professionals and subjects thought that the use of the self-management diaries would become better integrated in the delivery of care and that patients may experience more effects in terms of self-management through the adoption of these suggestions.

\section{Suggestions Made by Health-Care Professionals}

The first suggestion made by one pulmonologist was to include a web consult in the self-management diaries. A web consult would enable health-care professionals and patients to have a consultation without being in the same room. This may improve contact with health-care professionals by making them more easily accessible and may also save time.

The second suggestion made by both pulmonologists was to integrate the self-management diaries into the hospital information system, which provides health-care professionals with an integrated electronic overview of the disease state of the patient, including diagnosis, diagnostic test results, prescribed medications, and follow-up. Currently, pulmonologists must view 2 different (non-communicating) screens during a consultation: both the hospital information system and the web-based self-management diary. This requires a double logon and double registration of data. Due to time pressure, this sometimes results in not logging into the self-management diary. Hence, integration of the self-management diary with the hospital information system would improve accessibility and usability for pulmonologists.

The third and related suggestion made by both pulmonologists and pulmonary nurse practitioners was to im- prove the user-friendliness of the self-management diaries. Health-care professionals indicated that there are too many different screens and that they should be able to see at a glance how patients are doing.

\section{Suggestions Made by Subjects}

The first suggestion made by one subject was to start the self-management diary together with health-care professionals. When patients start the self-management diary together with their health-care professionals, they can be assisted in developing an individual treatment plan. Health-care professionals can show patients how to use the self-management diaries to cope more effectively with their disease. This may increase the ease of use for patients when first starting self-management diaries.

The second suggestion made by one subject was to include open space in the self-management diaries. This would provide patients with the opportunity to write their own comments and observations. By doing so, patients can provide potentially relevant information for understanding their disease, which may be another way to obtain knowledge about the cause of their poor health status. This may also provide health-care professionals with starting points to treat patients.

The third suggestion made by one subject was to develop the self-management diaries into a mobile app. This would make the self-management diary more easily accessible to patients and may persuade nonusers to start using a diary. 


\section{Self-Management Diaries in Asthma AND COPD}

Table 8. COPD Subjects' Reasons for Nonuse

\begin{tabular}{|c|c|}
\hline Reasons for Nonuse & Subjects' Comments \\
\hline Too difficult to use & $\begin{array}{l}\text { "I couldn't access the web site very easily, and I couldn't handle the computer very well, so it } \\
\text { [filling in the self-management diary] took me a couple of days." (COPD subject S) }\end{array}$ \\
\hline No acknowledgement of the disease & $\begin{array}{l}\text { "I don't acknowledge my disease; I try to cope with it as if I'm not diseased at all. Well, } \\
\text { that's of course a very strange idea if you have COPD GOLD stage IV, but you somehow } \\
\text { try to live very normally ..." (COPD subject U) }\end{array}$ \\
\hline No disease burden/forgetfulness & $\begin{array}{l}\text { "I don't think I'm going to use it because, at the moment, there's a necessity; then you do it, } \\
\text { and if there's not ... then it's extra. And then it's soon forgotten." (COPD subject X) }\end{array}$ \\
\hline Preference for face-to-face communication & $\begin{array}{l}\text { "I get regular checkups, and then I have all the information. With a personal talk, that's } \\
\text { easier; then I am able to communicate in my own words instead of book language. That's a } \\
\text { lot easier. I am a talker." (COPD subject T) }\end{array}$ \\
\hline
\end{tabular}

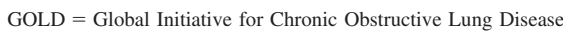

Table 9. Professionals' and Subjects' Experiences in Terms of Self-Management

Experiences in Terms of Self-Management

Improved insight into the disease
Professionals'/Subjects' Comments

"She can also see that you've sent this or that e-mail, that you've done that, and how it's going now. So your conversations become more useful... otherwise, it's like how is it going, are your medications still the same, did something happen, etc. Now we can immediately say, "you were bothered by that ...' You utilize your consultation better." (asthma subject E)

"So then we are watching [the diary]. It isn't going that well, is it? Based on that, he gives advice: increase the dosage of that medication." (COPD subject $\mathrm{R}$ )

“. . with me, the scores are always stable: $1.7,1.6,1.8$. Well, I don't see a major fluctuation in that. If I fill in some questions and the score is 4 , then I will give the hospital a call. There's something going wrong." (asthma subject F)

Different ways of coping with the disease or treatment

Perception of the disease

“... he [the subject] was saying, 'I really use it [the self-management diary] to have control over my own disease, that I do not panic every day when I'm short of breath; if I fill in that list, then I become calm'." (pulmonary nurse practitioner 1 )

"I cope with it [asthma] more consciously. When I open the diary, I'm thinking, 'how am I feeling? Well, not that good, somewhat worse than last week. How was it last week?' Then I open my diary and then I look; well, yes it was. It's a kind of reference point for me." (asthma subject A)

Lifestyle

“... people are now saying more I'm going to exercise, I'm going to quit smoking. You definitely see in those people and in other people who try it in a different way that they're convinced of having to change it themselves." (pulmonary nurse practitioner 2)

Medication adjustment

“... I've had an exacerbation, but now, with the diary, I know how to cope with it by keeping track of my medications." (asthma subject B)

\section{Suggestion Made by One Health-Care Professional and One Subject}

The final suggestion, made by one pulmonary nurse practitioner and one subject, was to include a broader range of topics related to environmental factors, such as nutrition, weather, and activities, in the self-management diaries. One pulmonary nurse practitioner suggested that this could be achieved by including more advanced contextualized instruments in the self-management diaries. Patients would then be urged to specify and differentiate between different causes of feeling bad and may be able to discover a relationship between behavior, circumstances, and their disease. When patients discover this relationship, they may be able to differentiate when environmental factors do or do not influence their health status.

\section{Discussion}

This study is one of the first known explorations of subjects' and professionals' perceptions and behaviors when using or not using self-management diaries for asthma and COPD. The majority of reasons for nonuse expressed by subjects are described in earlier research on self-management strategies. ${ }^{11-14}$ Because little research has been conducted specifically on the reasons for not using self- 
management diaries, reasons such as the format is too rigid and preference for face-to-face contact have not been previously described. The reasons for using self-management diaries expressed by subjects are not found in earlier research, ${ }^{11}$ which might be due to the small number of studies on this topic. Although subjects and professionals experienced several positive aspects in using the self-management diaries, a number of factors preclude their optimal and widespread use.

Subjects in this study used self-management diaries to improve their insight into the disease and to feel in control, which is in line with earlier research on self-management education of subjects with asthma. ${ }^{6}$ Furthermore, subjects coped more consciously with their disease and discussed the results of the self-management diary with their healthcare professionals. Nevertheless, only a proportion of the participating subjects succeeded in more effectively coping with their disease by independently recognizing an exacerbation and acting by adjusting their medications. This contrasts with research reporting positive changes in medication habits after self-management education of asthma and COPD subjects. ${ }^{21}$ The difference may be explained by the fact that subjects may not have understood sufficiently how to use the diary to deal more effectively with their disease. This might be overcome by more intense support at the onset of self-management diary use, especially for subjects with COPD, who tend to have lower health literacy. ${ }^{22}$ The subjects who used the self-management diary to independently recognize an exacerbation had asthma, and the subjects who thus adjusted their medications were young females with asthma. Although the numbers in our study are too small to draw conclusions, this finding is in line with earlier studies showing that females and younger people have higher self-management abilities.

In addition to these somewhat disappointing experiences in terms of subjects coping more effectively with their disease by recognizing an exacerbation and acting accordingly, health-care professionals experienced several practical barriers to integrating the use of the self-management diaries in their work practices. First, the user friendliness of the self-management diaries could be improved by reducing the number of screens and by enabling health-care professionals to immediately see how patients are doing. Second, the self-management diaries could be better integrated in the hospital information system of pulmonologists (and possibly made into an app), which would make the diaries more accessible to both pulmonologists and patients. The subjects also experienced practical barriers to using self-management diaries, which is also documented in earlier research ${ }^{23}$ that described a used intervention not being compatible with a subject's self-image and ways of coping with the disease. Subjects in this study indicated that the format of the self-management diaries was too rigid (eg, no open space to write comments and observations), and some subjects with COPD had difficulty in starting a self-management diary. Only subjects with COPD did not use self-management diaries because they preferred face-to-face contact with their health-care professionals. This is possibly related to the fact that most subjects with COPD are older than subjects with asthma and have lower health literacy. ${ }^{22}$ Subjects with asthma did not have any problems with an online self-management diary, which is in accordance with literature reporting that subjects with asthma recognize the potential benefits of a web-based self-management program. ${ }^{24}$ As research has shown that web-based interventions are more effective in terms of improving subjects' knowledge of the disease and treatment compared with non-web-based interventions, ${ }^{25}$ the self-management diaries should include as many opportunities as possible to link into health-care professionals' and subjects' practices. ${ }^{23}$

Health-care professionals' and subjects' suggestions for improving the self-management diaries show that both groups favor having easier access. Moreover, one pulmonary nurse practitioner and one subject suggested that the self-management diaries should address a broader range of topics to make them more relevant to the individual's health situation. However, some suggestions potentially contrast with one another or present practical challenges. For example, the suggestion made by health-care professionals that they should be able to see at a glance how patients are doing is seemingly contrary to the suggestion made by one subject to include open space in the self-management diaries. The inclusion of open space may make it more difficult for health-care professionals to have a clear oversight of patients' health status. The suggestion made by one subject to start the self-management diary together with health-care professionals may also be challenging from a health-care professional's point of view. Starting the self-management diary together requires more time, which is not always available during a consultation, but may contribute to the self-management diary becoming part of a patient's way of coping with disease. It has been shown that adherence to self-management programs improves when the health-care provider plays the role of a dedicated coach. ${ }^{26}$ This might prevent deleterious overconfidence on self-management programs without interaction with the health-care provider. ${ }^{27,28}$

Only subjects whom health-care providers thought would benefit and would be able to cope were offered self-management diaries. Additionally, subject selection for this study was performed by pulmonary nurse practitioners. The reported self-management effects may have been different if other subjects were selected. The interviewed health-care providers also potentially influenced the reported self-management effects. They may have been working with self-management diaries for a longer (or shorter) 


\section{Self-Management Diaries in Asthma and COPD}

period of time than health-care providers in other hospitals and thus have a greater (or smaller) possibility of increased self-management among their patients. Motivations of health-care providers who choose not to work with selfmanagement diaries was not discussed in this study and should be addressed in future research. Finally, patientprovider communication was not addressed in this study, and the clinical profile of the subjects (including the relationship between exacerbations and frequency and duration of self-management diary use) was not examined.

\section{Practical Implications}

Subjects' and professionals' perceptions and behaviors in using the self-management diaries have several practical implications. Recommendations to improve the use of self-management diaries were: include a web consult, enable communication with other systems (such as the hospital information system or an app), improve user-friendliness, provide patients with open space to write comments and observations, include more behavioral and environmental factors in the questions asked, and start the selfmanagement diary together with health-care professionals. This implies that the self-management diaries need to move with changes in technologies and that there is a need to create an instrument with room to improve functionalities. Health-care professionals should help patients start using such an instrument by collaboratively developing an individual treatment plan and by showing patients how to use the instrument to recognize and act on an exacerbation.

\section{Conclusions}

Health-care professionals and patients experienced several positive effects from the self-management diaries. However, both groups reported practical barriers to integrating the self-management diaries into their regular practices and daily life. Only a few subjects indicated using the self-management diary to cope more effectively with their disease through recognizing an exacerbation and adjusting medications. Adoption of the recommendations made in this study could improve the applicability of self-management diaries in health-care practice and enhance patients' self-management of their disease. Furthermore, this would facilitate longer-term study of the effects of this type of self-management intervention. Especially since the use of self-management diaries is a new development for both professionals and patients, such research into how selfmanagement diaries contribute to improving the self-management of patients over a longer time period is important.

\section{ACKNOWLEDGMENTS}

We thank Esther van Noort (Curavista) for giving permission to study the use of the self-management diaries and for providing additional infor- mation about the self-management diaries during an exploratory interview. We also thank Florian Visser (Zorgportaal Rijnmond) for the input in identifying subject groups and for providing additional information about the self-management diaries during an exploratory interview.

\section{REFERENCES}

1. Gibson PG, Simpson JL. The overlap syndrome of asthma and COPD: what are its features and how important is it? Thorax 2009;64(8): 728-735.

2. Apps LD, Mitchell KE, Harrison SL, Sewell L, Williams JE, Young HM, et al. The development and pilot testing of the Self-management Programme of Activity, Coping and Education for Chronic Obstructive Pulmonary Disease (SPACE for COPD). Int J Chron Obstruct Pulmon Dis 2013;8(Can't get issue from record):317-327.

3. Barlow J. How to use education as an intervention in osteoarthritis. Best Pract Res Clin Rheumatol 2001;15(4):545-558.

4. Hill K, Vogiatzis I, Burtin C. The importance of components of pulmonary rehabilitation, other than exercise training, in COPD. Eur Respir Rev 2013;22(129):405-413.

5. Boulet LP, Boutin H, Côté J, Leblanc P, Laviolette M. Evaluation of an asthma self-management education program. J Asthma 1995; 32(3):199-206.

6. Wilson SR, Scamagas P, German DF, Hughes GW, Lulla S, Coss S, et al. A controlled trial of two forms of self-management education for adults with asthma. Am J Med 1993;94(6):564-576.

7. Gibson PG, Powell H. Written action plans for asthma: an evidencebased review of the key components. Thorax 2004;59(2):94-99.

8. Adams SA. Blog-based applications and health information: two case studies that illustrate important questions for Consumer Health Informatics (CHI) research. Int J Med Inform 2010;79(6):e89-e96.

9. Thoonen BP, Schermer TR, Van Den Boom G, Molema J, Folgering $\mathrm{H}$, Akkermans RP, et al. Self-management of asthma in general practice, asthma control and quality of life: a randomized controlled trial. Thorax 2003;58(1):30-36.

10. Sedeno MF, Nault D, Hamd DH, Bourbeau J. A self-management education program including an action plan for acute COPD exacerbations. COPD 2009;6(5):352-358.

11. Ulrik CS, Backer V, Søes-Petersen U, Lange P, Harving H, Plaschke PP. The patient's perspective: adherence or non-adherence to asthma controller therapy? J Asthma 2006;43(9):701-704.

12. Buston KM, Wood SF. Non-compliance amongst adolescents with asthma: listening to what they tell us about self-management. Fam Pract 2000;17(2):134-138.

13. Horne R, Weinman J. Self-regulation and self-management in asthma: exploring the role of illness perceptions and treatment beliefs in explaining non-adherence to preventer medication. Psychol. Health 2002;17(1):17-32.

14. Dodd ME, Webb AK. Understanding non-compliance with treatment in adults with cystic fibrosis. J Roy Soc Med 2000;93(Suppl 38):2-8.

15. Green J, Thorogood N. Qualitative methods for health research. London: Sage; 2004; 3-26.

16. Pope C, Ziebland S, Mays N. Qualitative research in health care: analysing qualitative data. BMJ 2000;320(7227):114-116.

17. Wyatt SM. Non-users also matter: the construction of users and non-users of the Internet. In: Oudshoorn N, Pinch T. How users matter: the co-construction of users and technology. Cambridge, MA: MIT Press; 2003; 67-69.

18. Low J. Unstructured interviews and health research. In: Saks M, Allsop J. Researching health: qualitative, quantitative and mixed methods. London: Sage; 2007; 74-92.

19. Cramm JM, Nieboer AP. Self-management abilities, physical health and depressive symptoms among patients with cardiovascular 


\section{Self-Management Diaries in Asthma AND COPD}

diseases, chronic obstructive pulmonary disease, and diabetes. Patient Educ Couns 2012;87(3):411-415.

20. Schuurmans H, Steverink N, Frieswijk N, Buunk BP, Slaets JP, Lindenberg S. How to measure self-management abilities in older people by self-report: the development of the SMAS-30. Qual Life Res 2005;14(10):2215-2228.

21. Gallefoss F, Bakke PS. How does patient education and self-management among asthmatics and patients with chronic obstructive pulmonary disease affect medication? Am J Respir Crit Care Med 1999;160(6):2000-2005.

22. Roberts NJ, Ghiassi R, Partridge MR. Health literacy in COPD. Int J Chron Obstruct Pulmon Dis 2008;3(4):499-507.

23. Sassene MJ, Hertzum M. Incompatible images: asthmatics' non-use of an e-health system for asthma self-management. In: Wilson EV. Patient-centered e-health. Hershey, PA: IGI Global; 2009; 186-200.

24. van der Meer V, van Stel HF, Detmar SB, Otten W, Sterk PJ, Sont
JK. Internet-based self-management offers an opportunity to achieve better asthma control in adolescents. Chest 2007;132(1):112-119.

25. Wantland DJ, Portillo CJ, Holzemer WL, Slaughter R, McGhee EM. The effectiveness of web-based vs. non-web-based interventions: a meta-analysis of behavioral changes outcomes. J Med Internet Res 2004;6(4):e40.

26. in 't Veen J, Mennema B, van Noort E. Online self-management in COPD or asthma: with or without the healthcare provider? Eur Respir J 2012;40(Suppl 56):P1284.

27. Kruis AL, van Schayck OC, in 't Veen JC, van der Molen T, Chavannes NH. Successful patient self-management of COPD requires hands-on guidance. Lancet Respir Med 2013;1(9):670-672.

28. Fan VS, Gaziano JM, Lew R, Bourbeau J, Adams SG, Leatherman $\mathrm{S}$, et al. A comprehensive care management program to prevent chronic obstructive pulmonary disease hospitalizations: a randomized, controlled trial. Ann Intern Med 2012;156(10):673-683. 